\title{
OS DESAFIOS DA ESCOLHA PROFISSIONAL NA ADOLESCÊNCIA ${ }^{1}$ THE CHALLENGE OF PROFESSIONAL CHOICE IN ADOLESCENCE
}

\section{Paola Nascimento Brum² e Janaína Pereira Pretto Carlesso ${ }^{3}$}

\section{RESUMO}

O presente artigo teve como objetivo verificar quais são os desafios enfrentados pelos adolescentes no momento da escolha profissional. Essa pesquisa é uma revisão bibliográfica foi realizada a partir leitura de artigos e livros. Observou-se que a escolha profissional na adolescência é um fato complexo que contribui para a determinação de uma identidade. Esse processo pode gerar crises e conflitos, cuja análise deve considerar os fatores que alicerçam o adolescente, como a família, a sociedade, a educação e o meio de produção. Os principais desafios dessa escolha envolvem as peculiaridades do desenvolvimento psicossocial da adolescência, como a crise, a construção da identidade e o luto; a influência e o desenvolvimento escolar, as expectativas e crenças da família e do entorno social desse adolescente.

Palavras-chave: Identidade ocupacional, orientação vocacional, trabalho.

\section{ABSTRACT}

This article aims to verify what are the challenges faced by adolescents at time of professional choice. This research is a bibliographic review; it was carried out from reading articles and books. It was observed that the professional choice in adolescence is a complex fact that contributes to the determination of an identity. This process can generate crises and conflicts, whose analysis must consider the factors that underpin the adolescent, such as family, society, education and the means of production. The main challenges of this choice involve the peculiarities of psychosocial development of adolescence, such as the crisis, the construction of identity and mourning; the influence and school development, the expectations and beliefs of the family and the social environment of this adolescent.

Keywords: Occupational idendity, vocational orientation, job.

1 Trabalho resultado da disciplina de Escrita Científica I e Pesquisa em Psicologia.

2 Acadêmica do curso de Psicologia da Universidade Franciscana - UFN. E-mail: paolanbr1@gmail.com

3 Docente do curso de Psicologia da Universidade Franciscana - UFN. E-mail: janaina.carlesso@ufn.edu.br 


\section{INTRODUÇÃO}

A escolha pela profissão é uma decisão de grande relevância para o ser humano. Além de representar uma forma de sustento, integra a identidade de um sujeito e impacta no seu bem-estar. Essa questão incita reflexões desde a infância, porém, emerge significativamente na adolescência, momento em que se aproxima da vida adulta e da conclusão dos estudos em nível fundamental e médio. Sendo assim, essa decisão pode gerar muitas dúvidas e angústias, sobretudo, nessa etapa da vida, geralmente conturbada, em que ocorrem alterações importantes tanto físicas quanto emocionais, ademais, em que questões ligadas a identidade começam a surgir.

Nesse contexto, então, apresentam-se desafios envolvendo a escolha profissional ligados ao próprio processo de constituição identitária individual, à cultura e à expectativa familiar, às condições socioeconômicas, à situação das profissões e do mercado de trabalho contemporâneos e o percurso escolar dos adolescentes. Considerando a contemporaneidade, constata-se que a diversidade de profissões e rápidas transformações laborais em decorrência da tecnologia, provoca incertezas que podem agravar angústias ligadas a essa escolha, gerando crenças que a dificultam. Para auxiliar nessa jornada, existe a orientação profissional, ou vocacional, um campo de estudos e de atuação da Psicologia que visa compreender e orientar adolescentes e adultos nas suas escolhas profissionais conforme identificação de seus interesses e aptidões.

Por essa razão, torna-se relevante para a formação de um estudante do curso de Psicologia, o conhecimento sobre os desafios que os jovens enfrentam nesse contexto, já que, na futura atuação em estágios, e como futuro psicólogo, irá se deparar com essa demanda. Além disso, o conhecimento a ser obtido por esta investigação será relevante para o trabalho do profissional de Psicologia enquanto orientador e psicoterapeuta de jovens que estão em fase de decidir sua profissão, ou iniciando um percurso de carreira. Por fim, também é um assunto importante de ser compreendido pela sociedade, por colaborar com o entendimento de um desafio comum.

Com base nisso, este artigo teve como objetivo principal identificar os desafios apresentados pelos adolescentes diante dessa decisão, por meio de uma investigação da literatura sobre o tema da escolha profissional na juventude, considerando o contexto contemporâneo. Além disso, se faz pertinente o entendimento de que, durante todo o ciclo vital, em contexto de profissão, decisões de carreira são feitas e dúvidas são suscitadas. Sendo assim, a relevância desse trabalho justifica-se pelo motivo de a escolha profissional ser um tema complexo da adolescência que, muitas vezes, persiste irresoluto na vida adulta, podendo gerar sofrimento e insatisfação pessoal. 


\section{METODOLOGIA}

O tipo de pesquisa realizada é exclusivamente bibliográfico, feita por meio da consulta de livros e artigos, conforme Gil (2002). A abordagem metodológica é qualitativa, pois não trata de um levantamento numérico, mas ocupa-se de uma realidade do mundo social e seus significados. (MINAYO, 2001) Ademais, a abordagem adotada é a descritiva: visa descrever características e fenômenos de determinada população. (GIL, 2002) Neste caso, os desafios que a população adolescente enfrenta diante da escolha profissional.

Este trabalho foi realizado por meio da consulta de artigos eletrônicos, livros físicos, e-books, dissertações e teses em português disponíveis on-line nas plataformas: BVS Psicologia Brasil, Google Acadêmico, Scielo e Biblioteca Virtual da Universidade Franciscana. Os descritores utilizados foram: escolha profissional, orientação vocacional, o significado do trabalho, adolescência.

Nesta pesquisa foi utilizada, para análise dos dados coletados, a técnica de análise de conteúdo de Laurence Bardin, que consiste em três etapas: pré-analise, exploração do material e interpretação dos resultados. (BARDIN, 2016) Assim, inicialmente, foi realizada uma breve leitura dos resumos, introduções e sumários da bibliografia pesquisada. Em seguida, selecionados os materiais que melhor abordavam a temática e lidos integralmente. Com base nessa leitura, foi escrito o artigo presente artigo. A coleta de dados dessa pesquisa ocorreu no segundo semestre de outubro a dezembro de 2020.

\section{RESULTADOS E DISCUSSÃO}

O trabalho tem uma variedade de significados conforme diferentes autores, entretanto, uma significação existe em comum: consiste em uma atividade com objetivo, em que se emprega energia para produzir algo útil. (MORIN, 2001) Já o sentido do trabalho pode ser entendido como uma construção e uma reprodução da realidade social que depende de variáveis sociais, pessoais e da natureza da sociedade em determinado contexto histórico. Assim, o significado do trabalho como promotor de realização e satisfação pessoal, por exemplo, ou como um castigo, depende de fatores individuais, sociais e políticos. No entanto, constitui-se, perceptivelmente, em um dos valores fundamentais do ser humano e exerce grande impacto na sua subjetividade, pois contribui para a construção de uma identidade, para a autorrealização, criatividade, socialização, sustentabilidade, entre outras habilidades. (NEVES et al., 2018)

A configuração do trabalho está em transformação desde o século XX, observa-se o desaparecimento de empregos permanentes, a utilização de tecnologias e inovações na organização do traba1ho. Além disso, simultaneamente, milhares de pessoas sofrem com o desemprego, enquanto outras sofrem por trabalhar excessivamente. Apesar do contexto de instabilidade, disputa e desigualdade de oportunidades, o trabalho conserva um lugar de importância na sociedade, motivado, principalmente, 
pelo sentimento de vinculação, por gerar ocupação, promover o relacionamento interpessoal, evitar o tédio e contribuir para um objetivo de vida. (MORIN, 2001)

Conforme a visão desses autores nota-se a importância do valor social do trabalho e a produção de sentidos que uma ocupação proporciona ao ser humano. Diante da instabilidade observada na contemporaneidade sobre empregos, profissões e ao aumento da concorrência, torna-se possível inferir que sensações como medo e ansiedade pela falta de garantia de um lugar profissional permanente façam parte do contexto da escolha.

Paralelamente a necessidade do trabalho na sociedade e o seu valor subjetivo para os sujeitos, encontram-se as aflições a respeito das escolhas profissionais a fim de se atingir uma ocupação satisfatória. Para auxiliar os indivíduos com essas questões, existe uma especialidade da Psicologia conhecida como orientação profissional. Atualmente, o orientador ajuda os indivíduos a realizarem análises de seus desejos, resistências, possibilidades e dificuldades com vistas a traçar um projeto de carreira. (LEITE, 2018)

Grande parte das publicações relacionadas à intervenção do orientador profissional tem como enfoque estudos com estudantes do terceiro ano do ensino médio em vias de ingressar no ensino superior. Considera-se a influência histórica sobre essa concentração. Uvaldo, (2011): "No auge da década de 70, por exemplo, o sonho de todos era fazer uma faculdade, símbolo inconteste de ascensão social e respeito para a classe média e baixa".

Nesse contexto, o crescimento de instituições de ensino superior tornou possível almejar esse sonho, no entanto, na década de 1990, surgem determinados problemas, como pessoas graduadas não assimiladas pelo mercado de trabalho e a qualidade de ensino questionável de muitos cursos superiores. Diante dessa análise, a autora propõe ampliação do olhar do orientador vocacional para um desenvolvimento integral do indivíduo independentemente da idade. (UVALDO, 2011)

De fato, é na adolescência que a problemática profissional emerge como dificuldade, no entanto, essa escolha é uma ação continuada que inicia antes, culmina nesse período com a decisão quanto a um curso que levará a uma profissão, esse consiste no primeiro degrau da carreira, cujo percurso não é linear, e prossegue ao longo de toda a vida. (LEITE, 2018)

As inseguranças na vida ocupacional são observadas desde a oitava série, com estudantes entre 13 e 14 anos, principalmente entre os que ingressam no ensino técnico, até o momento da aposentadoria. A opção pela escola técnica geralmente é influenciada por adultos responsáveis pelo adolescente, ou do seu meio familiar, ou educacional, com o argumento de ser a melhor decisão para o futuro devido à possibilidade de um imediato ingresso no mercado de trabalho. (UVALDO, 2011)

Visto que a adolescência é uma fase emocionalmente complexa, devido às transições corporais, sociais e de identidade intensas, além de alterações cognitivas e psicossociais, é natural que se manifeste um sentimento de confusão. No entanto, apesar do tema da escolha profissional emergir nesse período, não se esgotará nesse momento. Nota-se a importância entendê-la como uma decisão que será reafirmada e 
reavaliada outras vezes durante o transcurso da vida, suscitando preocupações e dúvidas até a aposentadoria. Por esse motivo é fundamental que sujeitos aprendam a buscar subsídios, informações, autoconhecimento e desconstruir clichês para se sentirem confiantes diante de novas decisões.

A responsabilidade pela própria escolha é um aspecto fundamental no trabalho do orientador profissional atualmente. Há anos, a orientação era realizada por meio da aplicação de testes que visavam investigar a inteligência, habilidades e interesses para delinear o melhor caminho. Hoje, o foco da investigação é a própria pessoa, suas realidades internas e externas, e seu próprio jeito de elencar prioridades. O orientador incentiva o jovem a entrar em contato com sua aspiração principal, com um leque de aspirações, com diversas facetas de si mesmo e, sobretudo, espera-se que ele possa aprender a realizar a sua escolha e a comprometer-se com ela. (LEITE, 2018)

Papalia (2010) define a adolescência como o período compreendido entre 11 e 20 anos de idade. Essa é uma longa fase de transição entre a infância e a vida a adulta, marcada por intensas modificações físicas, cognitivas, emocionais e sociais, que assumem variadas formas em diferentes contextos sociais e culturais. Nesse período, levanta-se a problemática vocacional na preparação para a educação superior, ou para a entrada direta no mercado de trabalho, cuja influência sobre essas aspirações se deve a muitos fatores: capacidade individual, personalidade, educação, ambiente econômico e étnico, conselho de orientadores profissionais, experiências de vida e valores pessoais.

A respeito dessas influências sobre as metas vocacionais dos adolescentes, destacam-se os valores dos pais com relação ao desempenho escolar e as crenças de autoeficácia na definição de opções ocupacionais e sua preparação para atingir determinada meta escolhida. Além dessas, os estereótipos de gênero ainda influenciam a escolha da profissão, pois em países industrializados permanece a propensão de meninos decidirem por profissões nas áreas de engenharia, física e ciências da computação enquanto as meninas são maioria na escolha por carreiras na enfermagem, assistência social e ensino.

Outro fator importante é o próprio sistema de ensino que pode servir como um freio para determinadas aspirações, pois enfatiza as capacidades de memorização e análise. Então, estudantes com bom desempenho nessas capacidades são privilegiados no alcance das metas educacionais em detrimento daqueles cujo forte é o pensamento criativo e prático, esses raramente têm chances de mostrar o que podem fazer, ainda que existam campos profissionais em que essas habilidades são determinantes para o sucesso. (PAPALIA et al., 2010, p. 418)

O planejamento vocacional é um dos aspectos da busca pela identidade por parte do adolescente. A pergunta "O que eu vou fazer?" está muito próxima de “O que eu vou ser?". Pessoas que sentem que estão fazendo algo que vale a pena, e o fazem com seriedade, sentem-se bem consigo mesmas. Aquelas que sentem que seu trabalho não é importante - ou que não são boas naquilo que fazem - poderão questionar o significado de suas vidas.

O jovem que busca ajuda para fazer sua escolha deseja realizar-se no futuro. Essa é uma questão complexa que demanda o entendimento das diferentes instituições que alicerçam o adoles- 
cente, especialmente a família, o sistema educacional e o sistema de produção. Isso porque, o futuro imaginado não é abstrato: ao imaginar-se em uma profissão, o jovem deseja ser um(a) profissional como determinada(s) pessoa(s), real ou imaginário, conforme características valorizadas. Logo, essa decisão tem relação com o vínculo com os outros, pertencentes ao mundo ao qual deseja ingressar. Nesse sentido, para o adolescente, definir o futuro é, fundamentalmente, definir quem ele vai, ou não vai, ser. O dilema nessa fase é conciliar o que pensa sobre si mesmo e o que ouviu falar de si pelos outros. (LEITE, 2018, p. 18-19)

Todo jovem torna-se adulto mediante um processo psíquico de integração de seus aspectos pessoais, grupais, valorativos. Por isso, as inquietações relativas ao futuro profissional estão amalgamadas a várias outras, sendo possível conhecer sua problemática profissional se a enxergarmos inserida na dinâmica geral dos adolescentes. Estes são por excelência os candidatos para a orientação vocacional, pois se supõe que, ao final do ensino médio, realizarão a escolha sobre como prosseguir seus estudos. A orientação vocacional/profissional como um todo promove um insight no adolescente com relação ao seu modo de pensar, sua identidade ocupacional, bem como à dinâmica de sua personalidade.

Conforme Papalia (2010), a busca pela identidade entra em foco durante a adolescência, de acordo com os estágios de desenvolvimento psicossocial. Nesse período, a principal tarefa é enfrentar a crise de identidade, a sua resolução lança alicerce para lidar com os desafios da idade adulta. Conforme a teoria do desenvolvimento psicossocial, a identidade forma-se quando o jovem resolve três questões importantes: a escolha de uma ocupação, a adoção de valores e o desenvolvimento de uma identidade sexual.

Então, a escolha profissional é parte fundamental da formação da identidade, dificuldades nessa ação têm relação com o desenvolvimento da confiança, categoria oposta à crise. A resolução satisfatória da crise resulta na aquisição da virtude da fidelidade, uma extensão da confiança que significa lealdade constante, ou um sentimento de integração, com ideais, projetos e pessoas. Nesse estágio, pode ocorrer a confusão de identidade, ou confusão de papeis, atrasando a maturidade psicológica.

Quando os jovens têm problemas para fixar-se em uma identidade ocupacional - ou quando suas oportunidades são artificialmente limitadas -, eles correm risco de apresentar comportamentos com consequências negativas sérias, tal como atividades criminosas. (PAPALIA, 2010, p. 422)

Conforme a teoria dos estados de identidade, os estágios do desenvolvimento envolvendo crise e compromisso refletem a capacidade para o investimento pessoal em uma ocupação. Essa teoria categoriza os estados de identidade em quatro: realização da identidade, execução, moratória e difusão de identidade. Esses estados também são influenciados pelos fatores família e personalidade, sendo representativos do nível de sucesso na escolha profissional. (PAPALIA et al., 2010)

Em razão dessa transição, Bohoslavsky (1998) afirma que todo adolescente é uma pessoa em crise, pois o afeta intensamente tanto internamente quanto externamente. Além disso, o jovem precisa dar conta de resolver tarefas que envolvem a estruturação da sua identidade. Por crise entende-se 
uma ruptura com alguma forma de relação estabelecida, como se a personalidade fosse desestruturada e reestruturada. Com isso se faz uma relação com o luto, algo morre para que algo nasça. Na adolescência se vive diversos processos de luto, como com o corpo de criança e, também, no âmbito profissional, irá abrir mão de diversas opções ao escolher uma profissão.

O diferencia essa escolha de duas formas: a escolha profissional madura e a ajustada. A madura ocorre quando o sujeito não negou seus conflitos, os enfrentou e realizou a elaboração deles. Já a ajustada se dá quando o sujeito não trabalhou todos os seus conflitos, ainda nega alguns, mas utiliza seu autocontrole e responsabilidade para que seus gostos e as oportunidades exteriores coincidam, sem gerar o sofrimento característico de uma má-escolha. Ademais, a escolha de uma maneira de ser por meio da profissão também pode suscitar conflitos que revelam uma não integração de identidades. Quando essas identidades se integram, considera-se que o adolescente atingiu sua identidade ocupacional. (BOHOSLAVSKY, 1998).

De acordo com Leite (2018), a escolha profissional representa um dos rituais de passagem do jovem na nossa cultura. Em decorrência, ocorre uma diferenciação dos pais, a pertinência a um grupo e a ocupação de um lugar na sociedade. Muitas pessoas associam a dificuldade da primeira escolha ao fato de haver muitas ofertas profissionais, então se questionam se seria o caso de conhecer todas elas. Isso seria impossível ao passo que cada tema é um conjunto de assuntos inesgotável. No entanto, essa preocupação revela a crença da existência de uma única ocupação ideal para cada pessoa e, para encontrá-la, seria necessário conhecer todas existentes. Porém, a ampliação de opções de cursos superiores e técnicos, por exemplo, em sua maioria, são desdobramentos e especializações da grande área de uma profissão.

Sendo assim, a diversidade de profissões, a contínua transformação do mercado e a crescente oferta de cursos superiores podem parecer ameaçadoras para uma decisão, no entanto, as escolhas e os caminhos profissionais são singulares: o que motiva um sujeito em seu projeto difere da motivação de outro. Isso porque o exercício de uma profissão tem a ver com o desejo pessoal.

Outra crença popular comentada pela autora é a de que determinadas profissões, como as tradicionais, a exemplo da Medicina e do Direito, oferecem estabilidade financeira independentemente de crises econômicas, bem como outras estão fadadas ao fracasso econômico, como as ligadas à docência. No entanto, essas afirmações não passam de idealizações e preconceitos. Pautar-se em supostas tendências futuras de mercado pode ocasionar um problema, pois as profissões alternam em posições de alta e de baixa nas notícias de época para época. Já o dinheiro está mais relacionado a cada profissional do que a profissões específicas, pois alguns sujeitos apresentam dificuldades maiores em lidar com finanças, manejar sua carreira e imagem do que outros. Sendo assim, uma escolha profissional deve ter como foco os critérios do sujeito guiar-se pela sua personalidade e pelo que aprecia paralelamente a análise da realidade oferecida em termos de localidade, cursos, custos, condições de ingresso, oportunidades, que devem ser ponderados. (LEITE, 2018) 
Diante disso, observa-se que o cenário contemporâneo do mercado de trabalho, comentado no início deste artigo, gera preocupações, sobretudo, em adultos que convivem com jovens em processo de escolha. Entretanto, não consiste em um fator que deva definir uma decisão, tendo em vista que a motivação verdadeira para iniciar e persistir em uma carreira é subjetiva, individual, e pertence à ordem do desejo. Assim, é necessário avaliar as condições presentes e futuras em termos de finanças e oportunidades para determinar uma trajetória, mas a partir dos desejos particulares do sujeito.

Após ingressar em um curso de graduação, novos conflitos podem surgir. No contexto universitário, as dúvidas se manifestam em alunos no início, no meio e no final do curso. No começo da graduação, muitos dos estudantes sentem-se descontentes, muitas vezes, devido à adaptação a faculdade, ao novo ambiente e as novas relações. Nesses casos é importante que o orientador vocacional ajude o jovem a discriminar as razões das suas insatisfações para que não seja confundida com o curso escolhido em si. (UVALDO, 2011)

Nos casos em que alunos em meio de curso sentem insatisfação e dúvidas, possivelmente estejam experimentando uma desilusão com a graduação escolhida e, em muitos casos, possuem outra escolha em mente, mas procuram a orientação para se assegurar da decisão e enfrentar pessoas importantes para ela no seu meio, pois nesse estágio da graduação o estudante já tem subsídios suficientes sobre a área para amparar uma decisão. Entretanto, ressalta-se a importância do profissional ao conduzir uma reflexão sobre possibilidade de uma insatisfação generalizada do sujeito, cujo curso é apenas uma das suas manifestações, sendo necessário encaminhamento para a psicoterapia se for o caso. Entre os alunos em final de graduação, o desejo de iniciar outro curso, muitas vezes, reflete o luto pela condição de estudante e de adolescente. Nessa fase é comum que se manifeste o medo de sair da faculdade e a mudança da identidade de estudante que isso implica. (UVALDO, 2011)

Por fim, a maioria dos serviços de orientação vocacional oferecidos em países industrializados volta-se aos que almejam o ensino superior, para os que buscam o mercado de trabalho ainda existem poucas políticas de orientação e preparação para uma transição bem sucedida entre ensino médio e mercado. Em comunidades em que essa transição é bem sucedida, ofertam-se supervisão, estágio, qualificações básicas e colocação no emprego. Nesse sentido, sem conhecer o mercado de trabalho, a maioria dos adolescentes não consegue desenvolver conhecimentos teóricos e práticos para conseguirem se inserir em um emprego adequado às suas capacidades. (PAPALIA et al., 2010).

Diante disso, evidencia-se complexidade que envolver a decisão pela escolha profissional e os diversos fatores implicados nessa questão. Observa-se que, por esta compor um pilar importante na definição de uma identidade que será levada para a vida adulta, isto, por si só, já pode gerar bastante angústia no jovem. Além disso, a primeira decisão configura apenas o primeiro passo, após essa definição inicial o sujeito pode se deparar com novas dúvidas durante seu percurso de carreira, como na universidade, por exemplo. Sendo assim, o trabalho do psicólogo, como na orientação profissional, 
é bastante importante para auxiliar os adolescentes, e até mesmo os adultos, na identificação de seus desejos e estabelecimento de novos caminhos para sua identidade ocupacional.

\section{CONSIDERAÇÕES FINAIS}

A partir desse estudo, conclui-se que os desafios enfrentados pelo adolescente na escolha profissional se devem, especialmente, aos aspectos biológicos e sociais peculiares dessa etapa do desenvolvimento. A adolescência suscita muitas crises e conflitos, que por sua vez devem ser elaborados pelo adolescente para que ele possa atingir a capacidade de realizar uma escolha madura com identificação consigo mesmo.

Sendo assim, é importante que o adolescente tenha conhecimento do seu processo, tenha conhecimento sobre as profissões, possa realizar seu autoconhecimento e seja acolhido por seus familiares e entorno social. Para que isso ocorra é necessário o acesso a informação sobre conflitos que caracterizam a adolescência e os desafios que estar diante de realizar uma escolha profissional podem representar.

Além disso, o contexto do mundo do trabalho, apesar de instável, pode assustar e gerar medo no momento da escolha por determinada profissão ora estar em baixa, ora em alta. Entretanto, uma boa decisão deve considerar motivações internas do sujeito, os seus desejos, em detrimento de projeções de renda futura, apesar de ser importante considerar sua viabilidade de realização no contexto atual do adolescente.

Apesar da decisão da escolha profissional emergir nos anos finais do ensino médio, não se esgotará nesse momento. Conclui-se que é importante entendê-la como uma decisão que será reafirmada ou revista outras vezes durante o transcurso da vida, sendo importante, assim, o conhecimento da população acerca do tema da escolha profissional sob o viés da Psicologia, proporcionado pela socialização dos estudos teóricos sobre o assunto.

\section{REFERÊNCIAS}

BARDIN, L. Análise de conteúdo. São Paulo: Edições 70, 2016.

BOHOSLAVSKY, R. Orientação vocacional, a estratégia clínica. 11. ed. São Paulo: Martins Fontes, 1998.

GIL, A. C. Como elaborar projetos de pesquisa. 4. ed. São Paulo: Atlas, 2002.

LEITE, M. S. S. Série o que fazer? Orientação Profissional. 1. ed. São Paulo: Blucher, 2018. Disponível em: https://bit.ly/3t2ccp5. Acesso em: 22 out. de 2020. 
MINAYO, M. C. S. de (org.). Pesquisa Social. Teoria, método e criatividade. 18. ed. Petrópolis: Vozes, 2001. Disponível em: https://bit.ly/334VM13. Acesso em: 23 out. de 2020.

MORIN, E. M. Os sentidos do trabalho. In: RAE - Revista de Administração de Empresas, v. 41, n. 3, p. 8-19. São Paulo: EAESP, Jul./Set. 2001. Disponível em: https://bit.ly/3FU143G. Acesso em: 24 out. 2020 ;

NEVES, D. R.; NASCIMENTO, R. P.; FELIX, M. J. Jr.; SILVA, F. A. da; ANDRADE, R. O. B. de. Sentido e significado do trabalho: uma análise dos artigos publicados em periódicos associados à Scientific Periodicals Electronic Library. In: Cadernos EBAPE.BR, v. 16, n. 2, Rio de Janeiro: Escola Brasileira de Administração Pública e de Empresas, Abr./Jun. 2018. Disponível em: https:// bit.ly/3zsqVuU. Acesso em: 24 out. 2020.

PAPALIA, D; OLDS, S. e FELDMAN, R. Desenvolvimento humano. 10. ed. Porto Alegre: AMGH, 2010.

UVALDO, M. da. C. C. Relação homem-trabalho - Campo de estudo e atuação da Orientação Profissional. In: BOCK, A. M. B. [et al.]. A escolha profissional em questão. 3. ed. São Paulo: Casa do Psicólogo, 2011. Disponível em: https://bit.ly/3eQMFab. Acesso em: 22 out. de 2020. 